\title{
Migratory behaviour of Atlantic cod Gadus morhua: natal homing is the prime stock-separating mechanism
}

\author{
H. Svedäng ${ }^{1, *}$, D. Righton ${ }^{2}$, P. Jonsson ${ }^{1}$ \\ ${ }^{1}$ Swedish Board of Fisheries, Institute of Marine Research, PO Box 4, 45321 Lysekil, Sweden \\ ${ }^{2}$ The Centre for Environment, Fisheries and Aquaculture Science, Lowestoft Laboratory, Pakefield Road, Lowestoft, \\ Suffolk NR33 0HT, UK
}

\begin{abstract}
The migrations of $\operatorname{cod}(>37 \mathrm{~cm})$ in the Skagerrak and Kattegat were investigated in an archival tagging programme conducted between 2003 and 2006. Cod tagged at different localities showed non-random, directional movements in agreement with the hypothesis that the cod population in this region comprises a mixture of resident and migratory stocks. Cod tagged off the eastern Skagerrak coast migrated towards the North Sea, predominantly during the spawning period January to April, and most of these fish returned to the eastern Skagerrak later in spring. The putative spawning runs were associated with changes in habitat, as the migratory cod visited shallower and colder waters. In contrast, concurrently tagged cod in the Kattegat and the Gullmar Fjord (Skagerrak) showed a higher degree of resident behaviour. However, some fish also left these 2 areas for migration towards the North Sea, predominantly during the spawning period, in accordance with the theory that recruits from the North Sea will eventually leave the Kattegat and the eastern Skagerrak coast for their natal spawning sites. Taken together, these findings imply natal homing behaviour to be the intrinsic mechanism which underlies population separation in marine fishes.
\end{abstract}

KEY WORDS: Cod - Data storage tag $\cdot$ DST $\cdot$ Light geolocation · Natal homing

Resale or republication not permitted without written consent of the publisher

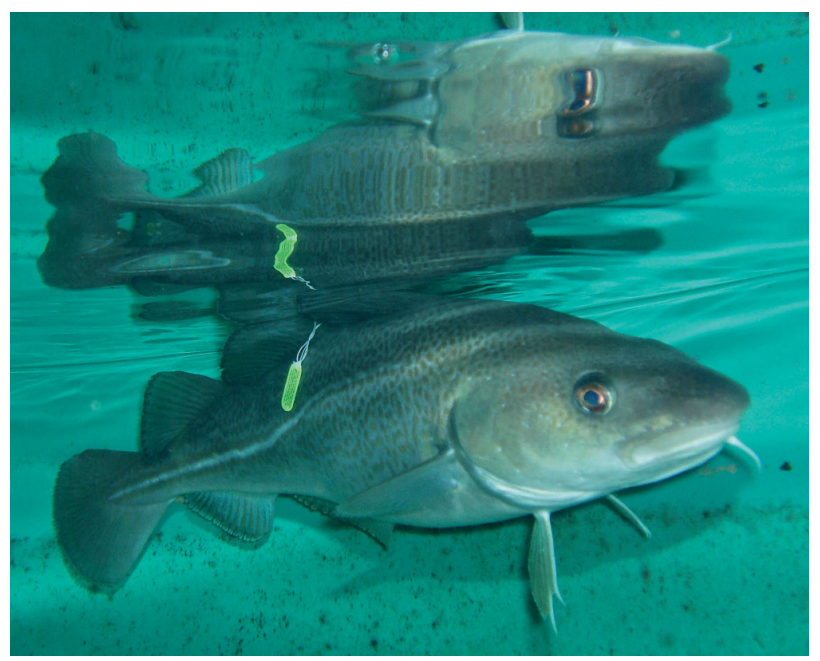

Cod Gadus morhua migrations can be assessed with archival tags, which store measurements of temperature, pressure (depth) and light.

Photo: Fisheries Research Services, Aberdeen

\section{INTRODUCTION}

The nature of marine fish population structures has been at the centre of fisheries biology for more than a century (e.g. Secor 2005). Central to our understanding of the origin of observed population structures are questions of the degree of connectivity between popu- 
lation units and the persistence of these units over time; contradicting opinions have thus emerged on population structuring mechanisms in marine temperate fish species such as Atlantic cod Gadus morhua L. (see Pawson \& Jennings 1996).

In a boundless sea environment, dispersal of eggs and larvae may well reach areas outside a population's core distribution area. Genetic isolation can only arise in such a case if retention of eggs and larvae is very effective, or if natal homing is a part of cod behavioural repertoire (Robichaud \& Rose 2004). Genetically divergent subpopulations have been identified, for instance, in the northwest Atlantic (e.g. Ruzzante et al. 2001), in Icelandic waters (Jonsdottir et al. 2001), in the North Sea (Hutchinson et al. 2001), and along the Skagerrak coast (Knutsen et al. 2003, 2004). In some of these studies, it was also shown that differentiation exists between relatively closely occurring subpopulations (Jonsdottir et al. 2001, Knutsen et al. 2003, 2004). For such differentiation to be preserved - even for small genetic differences - reproductive isolation is irrefutably implied.

The crucial point regarding the connection between putative cod stock units/subpopulations is therefore the mechanisms that separate population units from one another. The question is whether marine fish populations are segregated primarily by environmental forcing-i.e. retention during early life stages with accompanying opportunistic recruitment of juveniles to spawning aggregations (e.g. McQuinn 1997, Nielsen et al. 2005) - or through a combination of natal return migrations whose boundaries are set by larval drift and straying (Thorrold et al. 2001, Robichaud \& Rose 2004).

Circumstantial evidence for natal philopatry has been shown for cod in the eastern part of the Skagerrak (Svedäng \& Svenson 2006). An almost total eradication of locally spawning cod aggregations along the Swedish Skagerrak coast has, in some years, resulted in the apparent anomaly of low adult cod abundance coinciding with high juvenile abundance (Svedäng 2003, Svedäng \& Svenson 2006). Svedäng (2003) and Cardinale \& Svedäng (2004) hypothesised that most juvenile cod along the eastern Skagerrak coast had been passively transported from offshore spawning areas (Munk et al. 1999), and the following (unexpected) low abundance of adult cod was due to return migration of juvenile and/or maturing fish which had reached a certain size or age (Pihl \& Ulmestrand 1993). This theory was supported by the fact that strong year classes of juvenile cod along both the Norwegian and Swedish Skagerrak coast have been genetically assigned to eastern North Sea cod populations (Knutsen et al. 2004). Thus the disappearance of local spawning aggregations, presumably due to over-fishing, provided a natural set-up for analysing homing behaviour and recolonisation processes.
It is, however, only by studying horizontal movements over time that questions about the unity of the stocks, and stock separating mechanisms, can be fully addressed (cf. Secor 2005). To obtain observational records, archival tag technology represents a relatively new opportunity to reconstruct fish migratory pathways which may-separately or jointly with other methods-reveal more complex migratory patterns (e.g. Wright et al. 2006).

By analysing records on various physical factorsalone or in combination-such as light (Musyl et al. 2001 and references therein), depth (i.e. pressure), tidal signals and temperature (e.g. Hunter et al. 2003), the migratory movements of individual fish can be mapped from retrieved tags. The purpose of our study was to examine - using observational data on migratory behaviour - the following 2 hypotheses: (1) that the cod population in the eastern North Sea region comprises a mixture of resident and migratory stocks (Munk et al. 1999, Knutsen et al. 2004, Svedäng \& Svenson 2006); (2) that if natal homing is a part of the behavioural repertoire of cod, recorded movements should be directional and related to spawning locations.

\section{MATERIALS AND METHODS}

Tagging procedures. Archival tags were deployed on cod between 2003 and 2005 along the Swedish west coast, i.e. in the inshore and off the eastern Skagerrak coast, and in the Kattegat and Öresund. In the present study, migratory behaviour was examined for fish that were tagged on the eastern Skagerrak coast and adjacent areas (i.e. the Kattegat and the Gullmar Fjord on the Skagerrak coast), since some of the fish from latter areas exhibited similar migration-behaviour patterns to cod tagged in the Skagerrak (Fig. 1a, see also Table 1).

The fish used for tagging purposes were captured either in cages or in trawling sets (maximum duration of $30 \mathrm{~min}$ ). Fish were visually inspected, and only those showing normal swimming behaviour were used in the experiments. At release, records on length $(\mathrm{cm}$ interval), weight (g), sex (if sexually mature) and GPS positions were taken. The archival tags (Lotek model LTD 2410; www.lotek.com) were attached externally with a stainless steel wire (Fig. 2). The wire was led through plastic sheaths incised in the fish's back just underneath the first dorsal fin base.

Fishers who reported recaptures were rewarded in exchange for tag and fish, respectively, and also had to indicate the date and position of the recapture. Otoliths (sagittae) were removed from all retrieved fish carcasses, and aged by a single reader, counting hyaline zones on sectioned otoliths illuminated from above against a dark background. For retained fish that had 

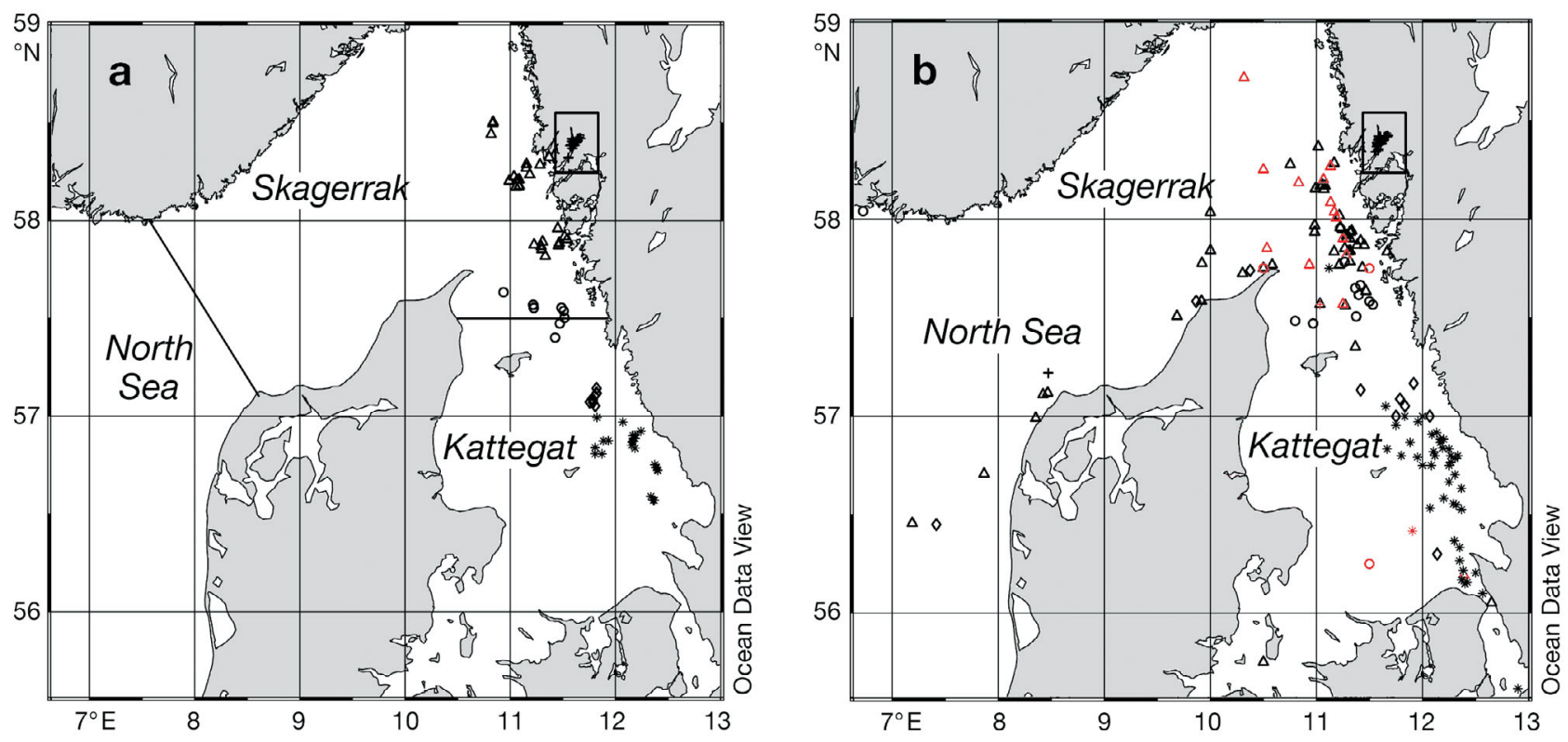

Fig. 1. Gadus morhua. (a) Tagging localities along the Swedish west coast, 2003 to 2005. ( $\Delta$ ) Eastern Skagerrak coast; ( $(0)$ southern Skagerrak; (+) Gullmar Fjord; $(\diamond)$ northern Kattegat; (*) mid- and southern Kattegat. (b) Reported positions of recaptured tagged cod in the Kattegat, Skagerrak and North Sea. Symbols refer to original tagging localities shown in (a). Red symbols in (b): fish geolocated west of longitude $10^{\circ} \mathrm{E}$ during their time at liberty. Large black rectangle: Gullmar Fjord

not been gutted, gonadal inspection was conducted. Sexual maturity of each cod was classified according to a 4-stage macroscopic scale, used in the International Bottom Trawl Survey (IBTS; Vitale et al. 2006); a more detailed histological analysis was not possible because most of the fish had been deep frozen before being delivered to the laboratory. Fish in Stages 1 and 2 were considered as non-maturing, whereas fish in Stages 3 and 4 were considered as maturing or mature.

Archival tag characteristics and handling. The archival tag used in this study was equipped with real time clock (set to UTC), pressure sensor, external temperature sensor, internal temperature sensor (i.e.

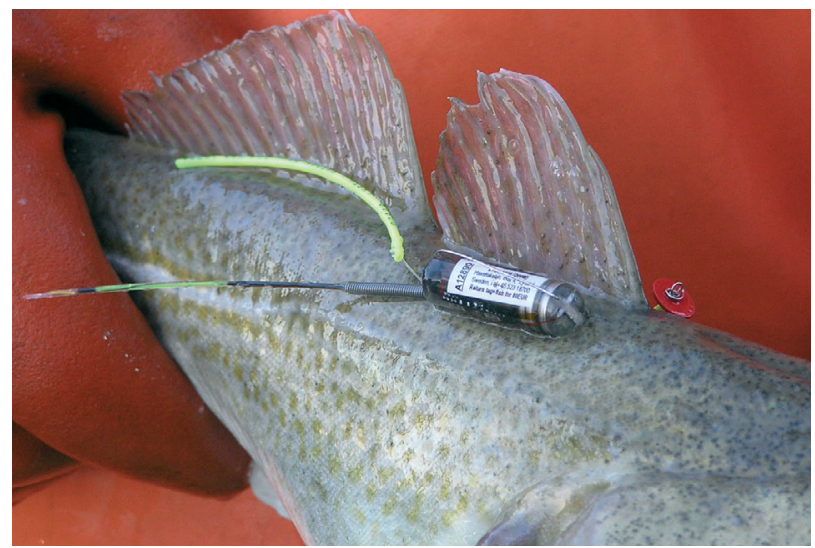

Fig. 2. Gadus morhua. External attachment of an archival tag to a fish. Anterior and posterior wires of the tag have been tied up separately inside the capsulation), and a light intensity sensor (measurements band $470 \pm 50 \mathrm{~nm}$ ). As the data can be collected at various intervals, there are several ways to optimise the limited memory capacity (83000 data points). In this experiment, the deployed tags were programmed to save data at either 60 or $300 \mathrm{~s}$ time intervals, giving a maximum of 46 or $230 \mathrm{~d}$ stored data, respectively. Up to May 2004, all fish were deployed with tags storing data at $60 \mathrm{~s}$ intervals; for the rest of 2004, tags stored at both 60 and 300s intervals; and in 2005 , only the $300 \mathrm{~s}$ interval was used.

The tag could also be programmed to telescope the data; i.e. once the memory capacity was exhausted, some of the data collected were permitted to overwrite already stored data in a specified linear manner. This allows the total storage capacity of the tag to be evenly distributed over the entire mission without sacrificing the temporal resolution of the data for any day that time series data were logged. The retained data were saved in blocks of minimum 2 d (i.e. 48 h). The tag also stored several parameter values on a daily basis during the deployment: e.g. estimated longitude and latitude (i.e. onboard processed estimates; see 'Light-intensity based geolocation' below), sunrise and sunset in UTC, maximum external temperature, and maximum and minimum depths. Data from retained tags were downloaded using the TagTalk 2000 version 1.1.125 software (www.lotek.com). The downloaded data was visualised or exported using Viewer 2000 version 2.5.0 software (www.lotek.com). 
Light-intensity based geolocation. In principle, estimation of local noon (or local midnight) gives records on the longitude, whereas estimation of day length gives the latitude, except at times close to equinox. The onboard tag algorithm estimated longitude by defining dusk and dawn at civic twilight (zenith angle equal to $93.44^{\circ}$ ) as particular (characteristic) changes in light intensity, and by recording the times at which they occurred. The Greenwich hour angle (GHA) between local noon and UCT gives longitude. Although celestial methods are highly accurate in principle, the precision is impaired due to measurement errors caused, for instance, by variation in cloud cover and seawater transparency, and obtained raw geolocations often deviate with hundreds of kilometres from their true positions (Musyl et al. 2001).

The longitude estimation is, however, much more precise, as well as less prone to systematic deviation, than latitude estimation. In order to obtain repeated longitude estimations, retrospective inspection of retrieved diurnal light intensity curves (Fig. 3), were made by applying several horizontal intersections of the bell-shaped light curve, assuming the same elevation of the sun above the horizon at equal light intensity levels. Three intersections were made for each light intensity curve, giving a date-specific mean time value of local noon, which could be used for longitude estimation. If the estimated local noon for these intersections differed by $>5 \mathrm{~min}$ from one another, the light intensity curve was judged as distorted and unusable for geolocation purposes. The precision of the longitude estimates based on the inspections of diurnal light curves was checked by comparing the difference between the retrospectively estimated longitude and the release longitude for the first $10 \mathrm{~d}$ at liberty for all retrieved tag time series.

Data obtained using this method suggested that the fish made negligible horizontal movements during the first period at sea.

Kalman filtering. Due to obvious data storage limitations, not all days at liberty at sea could be retrospectively inspected. In order to evaluate the automatic onboard geolocation estimates, which could be distorted to an unknown and varying extent, application of an extended Kalman filter tracking model was considered as an alternative for sorting out geographic signals from tag position time series (Sibert et al. 2003). The software package KFtrack 0.61 (www.r-project. org) was used for track estimation from day-logged positions. However, since many onboard position estimates were calculated on distorted light data, the data sets had to be filtered in order to exclude clearly nonsensical estimates, and to attain modelling results. Consequently, all estimates that departed $> \pm 15^{\circ}$ from longitude $11^{\circ} \mathrm{E}$, and $> \pm 20^{\circ}$ from latitude $57^{\circ} \mathrm{N}$ were

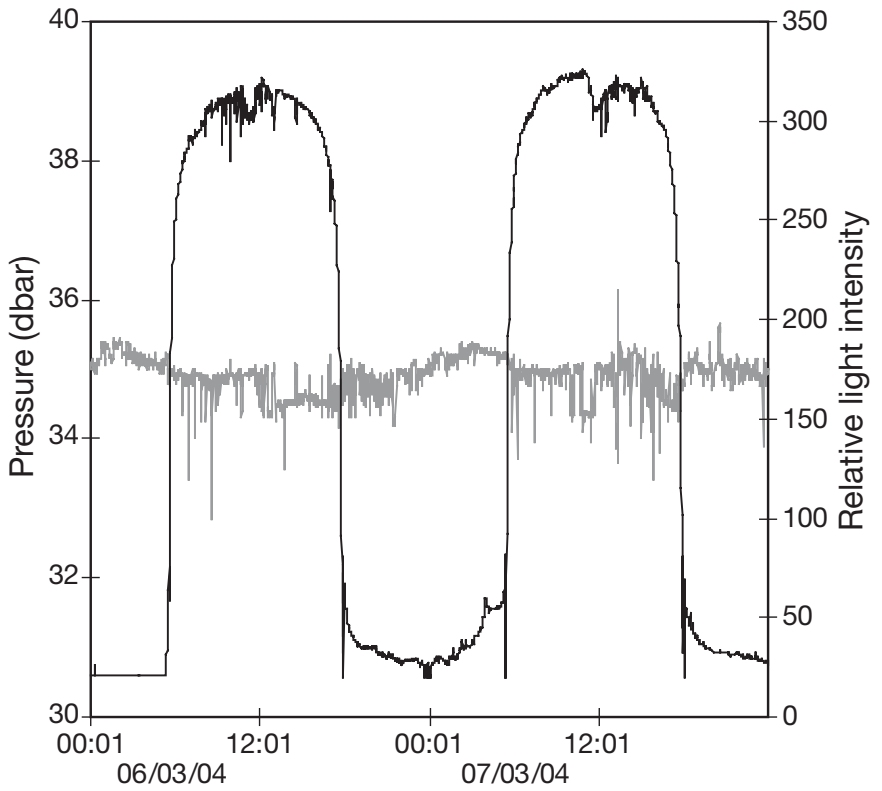

Fig. 3. Recorded relative light intensity (black) and pressure (grey) during 2 days (dates are dd/mm/yy) in 2004; extracted from an archival tag attached to a fish released in the eastern Skagerrak, November 2003

excluded from the data sets. Finally, only model results on longitude were considered reliable (and thus used as evidence of fish movements). The model converged for 15 out of 60 data sets ( $25 \%$ ). This rather low rate of convergence was explained by the fact that for many data sets, daily position estimates were not available due to poor ambient light conditions at sea-i.e. they were either excluded at sea by the tag onboard modelling or considered nonsensical estimates and discarded in the pre-filtering process.

Tidal location model. Tidal ranges (high water to low water, or vice versa) were extracted using a wavefitting algorithm. Starting at each successive point in the archival tag pressure record, the algorithm searched for the best fitting sine wave, applying a least-squares regression, using data from the following $9 \mathrm{~h}$ period. The period of the modelled waveform was constrained so that the half-tidal period could not fall below $4.5 \mathrm{~h}$ or exceed $7.5 \mathrm{~h}$. The offset of the model was constrained so that the waveform began with a maximum (or minimum) and continued beyond a minimum (or maximum). For each day, the best-fitting waveform was used to calculate the times of high and low water, the tidal range, and an indication of the quality of fit (sum of squares). Estimates of tidal range and time of high water were filtered to obtain the most accurate daily estimate (based on least sum of squares). These data were then used in the tidal location method (TLM: Hunter et al. 2003), used to derive, by day, possible geographic locations where the individual may have been. During the winter and spring, 
when most of the North Sea is vertically mixed, daily average temperatures recorded by the archival tags were then compared to averaged sea surface temperature (SST; taken from Bundesamt für Seeschiffahrt und Hydrographie, Hamburg), and positions at which tag temperature and SST differed by more than $1^{\circ} \mathrm{C}$ were excluded.

\section{RESULTS}

\section{Reported recapture positions}

The number of tagged fish, return rates and mean and maximal duration at liberty at various localities and tagging occasions are shown in Table 1. The recapture positions clearly indicated a southwesterly direction of movement from the release points in the eastern Skagerrak towards the western part of the Skagerrak and the North Sea (Fig. 1). A high degree of residency was indicated for fish tagged in the middle of the Kattegat as well as in the Gullmar Fjord on the Skagerrak coast, although some fish showed similar movements towards the North Sea. Some fish tagged in the Skagerrak were reported recaptured from the Kattegat.

\section{Light-intensity based geolocation}

The precision of longitude estimates was evaluated by inspecting obtained calculations based on diurnal light curves for the first $10 \mathrm{~d}$ at liberty (Fig. 4). The mean difference between the retrospectively estimated longitude and the release longitude $( \pm \mathrm{SE})=$ $-0.15 \pm 0.10^{\circ}$ (no. of observations $=114$, no. of time series $=54$ ). Due to this rather high degree of precision, the retrospective inspection method was considered valid for detecting movements larger than $1^{\circ}$ longitude from the release point. These inspections were then used for characterisation of fish horizontal movements, considering 3 or more consecutive estimates departing $>1^{\circ}$ longitude from the previous location as a new valid geolocated longitude. In this way the migratory behaviour was reconstructed for the entire duration at liberty.

Stored daily estimations of the longitude and latitude provided the opportunity to contrast the light geolocation results with the outcome of the Kalman filtering modelling. In those cases when the Kalman filtering modelling produced a tracking record of the longitude, the results corresponded fully with the classification of the migratory behaviour based on retrospective estimations of the longitude, although individual Kalman modelling estimates could depart
Table 1. Gadus morhua. Number of tagged and recaptured fish, recapture rate and mean and max. no. of days at liberty at sea, recorded at various localities and tagging occasions

\begin{tabular}{|lrrrrr|}
\hline \multicolumn{7}{l}{ Tagged Recaptured $\begin{array}{c}\text { Recapture } \\
\text { rate }(\%)\end{array}$} & \multicolumn{2}{c|}{$\begin{array}{c}\text { Days at sea } \\
\text { Mean }\end{array}$} \\
& & & & & \\
& & & & & \\
Gullmar Fjord & & & & 126 & 265 \\
Feb-April 04 & 50 & 17 & 34 & 110 & 362 \\
May 04 & 53 & 19 & 36 & 83 & 196 \\
Oct 04 & 18 & 6 & 33 & 51 & 100 \\
May 05 & 31 & 13 & 42 & & \\
Total number & 152 & 55 & & & \\
Skagerrak & & & & & \\
Nov 03 & 63 & 26 & 41 & 151 & 446 \\
Apr-May 04 & 28 & 14 & 50 & 124 & 308 \\
Oct-Dec 04 & 75 & 15 & 20 & 149 & 384 \\
Feb-May 05 & 90 & 30 & 33 & 103 & 236 \\
Total number & 275 & 88 & & & \\
Kattegat & & & & & \\
Dec 03 & 47 & 31 & 66 & 98 & 512 \\
Feb 04 & 54 & 31 & 57 & 36 & 227 \\
May 04 & 16 & 5 & 31 & 123 & 162 \\
Nov 04 & 25 & 7 & 28 & 111 & 479 \\
Total number & 142 & 74 & & & \\
\hline
\end{tabular}

considerably from the retrospective light estimations (see Appendix 1, available as supplementary material at: www.int-res.com/articles/suppl/m345p001_app.pdf).

A subset of common migratory patterns was identified. For fish classified as moving from the eastern Skagerrak towards the North Sea and back again, the tracking results showed a general movement towards the west during early spring (Fig. 5a,b). Fish showing track records similar to Fish ID87 were depicted as resident (Category ' 1 '), since this fish showed fairly stable longitude values at about $11^{\circ} \mathrm{E}$ (Fig. 5c). There was an indication that Fish ID60 might have returned to

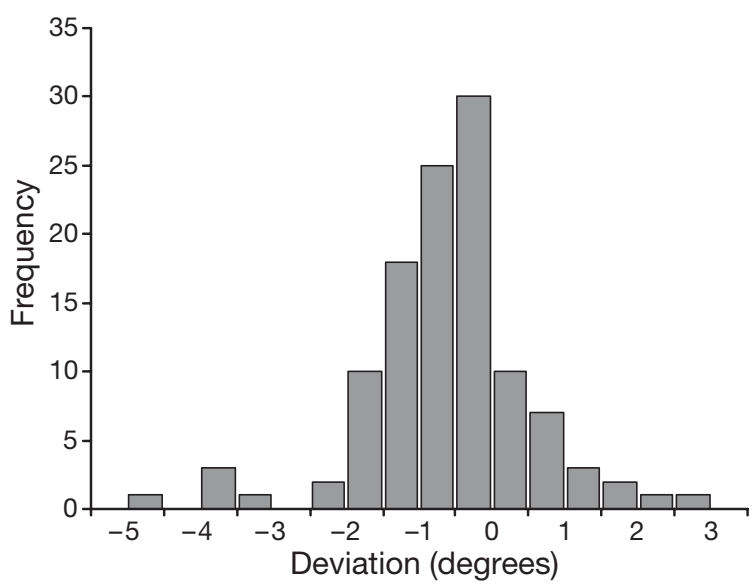

Fig. 4. Frequency distribution of deviations in longitude estimates (deviations measured from release point, based on retrospective inspections of diurnal light curves for the first $10 \mathrm{~d}$ at liberty); $\mathrm{N}=114$, based on 54 different time series 
the Skagerrak in early summer 2004, and thereafter swum towards the North Sea again, where it was eventually caught (Fig. 5d). For the whole data set, the retrieved fish were thus classified into the following categories:

(1) Resident within the release areas (i.e. the eastern Skagerrak, Gullmar Fjord or the Kattegat)

(2) Released in the Skagerrak and recaptured west of longitude $10^{\circ} \mathrm{E}$ in the Skagerrak/North Sea

(3) Released and recaptured in the eastern Skagerrak, but geolocated west of longitude $10^{\circ} \mathrm{E}$ in the Skagerrak/North Sea

(4) Released in the Skagerrak and recaptured in the Kattegat

(5) Undefined movements in the deeper part of the Skagerrak (or North Sea)

(6) Released in the Kattegat and recaptured in the Skagerrak/North Sea

(7) Released and recaptured in the Kattegat but geolocated in the Skagerrak/North Sea

The outcome of these characterisations for fish which had been at liberty for $>30 \mathrm{~d}$ is shown in Table 2. For fish released in the eastern part of the Skagerrak, $38 \%$ of the recaptures were classified as resident (Category 1). However, larger proportions of the recaptured fish showed a dispersal pattern directed to the west: $18 \%$ were recaptured in the western Skagerrak or the North Sea (Category 2; Fig. 1b), and $28 \%$ were geolocated to the western Skagerrak or the North Sea (Category 3), i.e. exhibited return migrations to the eastern part of the Skagerrak after having visited areas west of longitude $10^{\circ} \mathrm{E}$. Two fish were found to have moved south from the eastern Skagerrak during the spawning season: 1 fish was recaptured in the southern part of the Kattegat, whereas the other was caught in the Öresund (Category 4). About $13 \%$ of the retrieved fish showed undefined movements in the deeper part of the Skagerrak (Category 5), or were left unclassified. More important, however, than the recapture proportion of various categories: the incidence of fish showing a resident behaviour declined with duration at liberty (Fig. $6 \mathrm{a} ; \mathrm{r}_{\mathrm{S}}=-0.44 ; \mathrm{n}=77 ; \mathrm{p}<0.001$; unclassified fish excluded).

For cod tagged in the Gullmar Fjord, just 2 fish were actually reported recaptured off the coast, although it should be noted that these fish also had among the highest values of number of days at liberty (Fig. 6b). One of these 2 fish was recaptured in early spring in the western part of the Skagerrak, whereas the other, although
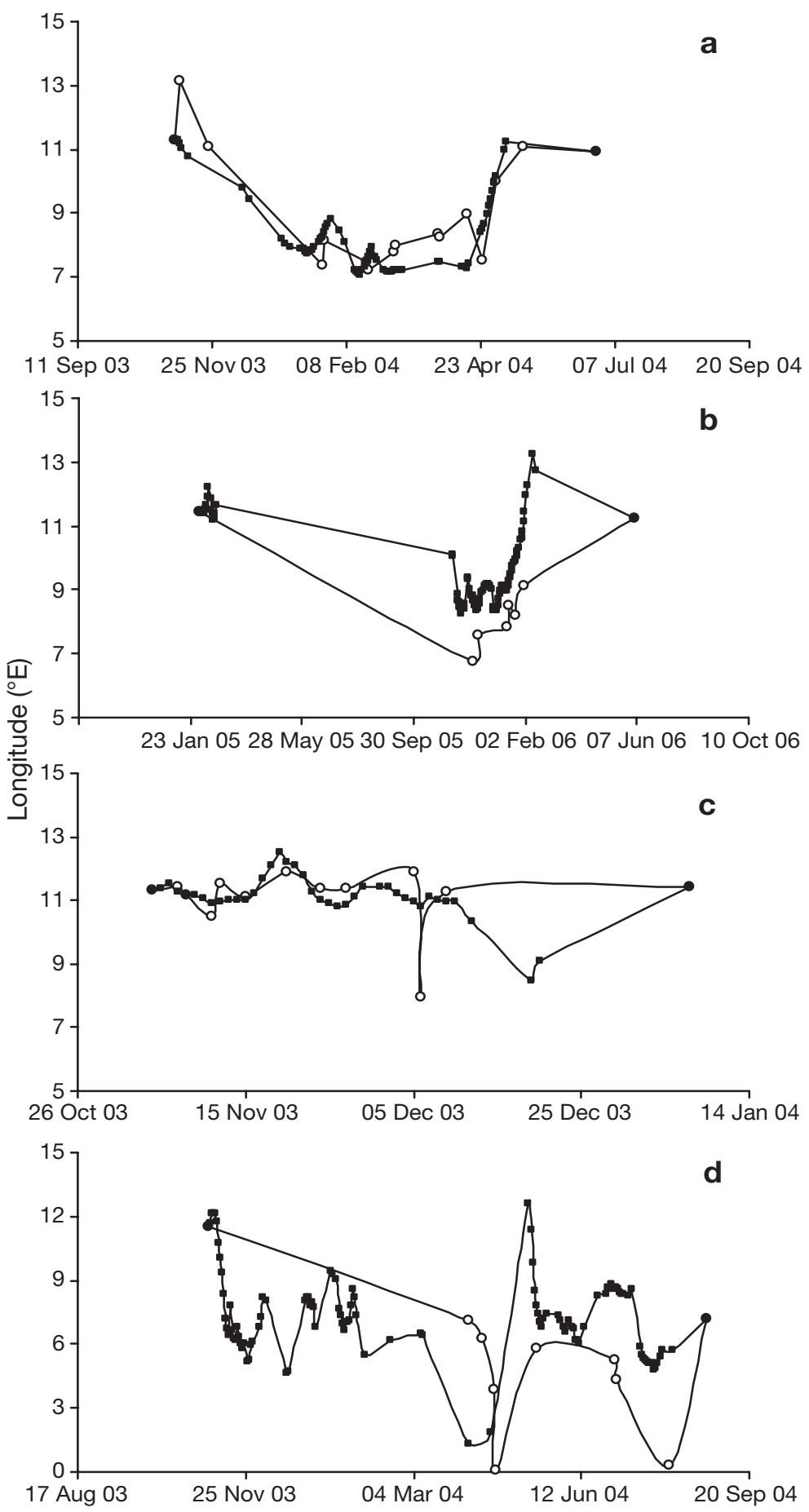

Fig. 5. Gadus morhua. Estimation of longitude by retrospective light geolocation and by Kalman filter modelling of day-logged positioning of archival tagged cod released in the eastern Skagerrak 2003 to 2005; (O) retrospective light curve inspections, (ロ) Kalman filtering results. Starting points: research vessel GPS values; end points: reported recapture positions. (a) ID86 and (b) ID679: classified as moving from the eastern Skagerrak to the North Sea, and back again (Category 3, see 'Lightintensity based geolocation' for further explanation); (c) ID87: classified as resident (Category 1); (d) ID60: classified as having migrated into the North Sea, where it was eventually caught (Category 2). Note different $y$-axis scale in $(\mathrm{d})$ 
reported recaptured in the southeastern Skagerrak, was geolocated to the North Sea during early spring before being recaptured. In the Kattegat, most of the released fish showed a resident behaviour irrespectively of time at liberty (Fig. 6c), although about $12 \%$ were either recaptured or geolocated in the Skagerrak or North Sea. Notably, most of those fish showing such migratory behaviour had been tagged in the northern part of the Kattegat (Fig. 1b). Finally, no deviation from a hypothetical even sex ratio could be substantiated in any subgroup (Table 2).

\section{Tidal location modelling}

The depth and temperature data provided by the tags enabled tidal based geolocation. The number of possible locations identified per individual varied between tags (Table 3) and, as is usual for tidal geolocations, yielded clusters of possible locations equidistant from amphidromic points. The nature of the telescoped data recorded in the tags' memory meant that there were often intervals of several days between successive geolocations, so it was not possible to eliminate locations from different clusters using a swimming speed rule (as for Hunter et al. 2005). Overall therefore, tidal geolocations were concentrated in 3 areas: the mouth of the Skagerrak, the Dogger Bank, and the German Bight (Fig. 7). Despite this limitation, most tags yielded locations that were consistent with the longitude estimates provided by the light-based geolocations, i.e. they indicated a movement from the east- ern Skagerrak to the North Sea or the western part of the Skagerrak, and the average position of the tidal geolocations was consistent with the estimates of migration provide by light-based geolocation. The tidal locations could therefore be used to corroborate the type of migratory strategy exhibited by each cod, and accorded with the light-based classifications in 16 of 23 cases. In addition, the tidal location estimates provided an estimate of latitude that, in most cases, supported the hypothesis that cod migrated to known spawning areas between 53 and $58^{\circ} \mathrm{N}$.

To further evaluate the geolocation results, it was conjectured that fish moving to the North Sea should have experienced different depths and temperatures than fish resident in the eastern Skagerrak. The lack of continuous high frequency time series on experienced depths, however, restricted the generality of the retained time series. Instead, the daily recorded minimum and maximum depths and maximum temperatures for fish belonging to Categories 1 to 3 were used as proxies of habitat choice during the resident and migratory phases, respectively (Fig. 8).

It was shown that fish depicted to be west of longitude $10^{\circ} \mathrm{E}$ on average experienced slightly lower sea water temperatures during winter in all 3 years and higher temperatures in summer 2004 than fish assigned as resident (Fig. 8a). The differences in maximum and minimum depths recorded between resident and migratory fish were even more pronounced: fish assigned as being migratory spent their time in shallower waters during winter in all 3 years than fish assigned as resident (Fig. 8b,c).
Table 2. Gadus morhua. Fish horizontal movements based on retrospective inspections of day-logged longitude estimates for fish $>30 \mathrm{~d}$ at liberty. (\%) proportion classified within area. No. of spec.: no. of specimens, Fe: female, Ma: male, Unk: unknown. Categories-1: resident in the Skagerrak; 2: recaptured off the Danish Skagerrak coast or in the North Sea west of longitude $10^{\circ} \mathrm{E}$; 3: geolocated in the western part of the Skagerrak (i.e. west of longitude $10^{\circ} \mathrm{E}$ ) or in the North Sea; 4 : released in the Skagerrak and recaptured in the Kattegat; 5: undefined movements in the deeper part of the Skagerrak (or the North Sea); 6: released in the Kattegat and recaptured in the Skagerrak or the North Sea; 7: released and recaptured in the Kattegat, but geolocated in the Skagerrak or the North Sea; Unclassified: no classification attempted

\begin{tabular}{|c|c|c|c|c|c|c|c|c|c|c|c|c|}
\hline $\begin{array}{l}\text { Migratory } \\
\text { classification }\end{array}$ & \multicolumn{4}{|c|}{$\begin{array}{l}\text { Skagerrak } \\
2003-2005\end{array}$} & \multicolumn{4}{|c|}{$\begin{array}{c}\text { Gullmar Fjord } \\
\text { 2003-2005 }\end{array}$} & \multicolumn{3}{|c|}{$\begin{array}{l}\text { Kattegat } \\
2003-2004\end{array}$} & $4(\%)$ \\
\hline 1 & 5 & 8 & 14 & 38 & 19 & 13 & 11 & 96 & 12 & 13 & 13 & 76 \\
\hline 2 & 3 & 3 & 7 & 18 & & & 1 & 2 & & & & \\
\hline 3 & 5 & 4 & 11 & 28 & & 1 & & 2 & & & & \\
\hline 4 & 1 & & 1 & 3 & & & & & & & & \\
\hline 5 & & & 5 & 7 & & & & & & & & \\
\hline 6 & & & & & & & & & 3 & & 2 & 10 \\
\hline 7 & & & & & & & & & & & 1 & 2 \\
\hline Unclassified & 2 & & 2 & 6 & & & & & 1 & 1 & 4 & 12 \\
\hline
\end{tabular}

\section{Biological differences between resident and migratory cod}

Differences in biology were examined for cod tagged in the Skagerrak characterised either as resident (Category 1) or migratory (Categories 2, 3 and 4) cod, i.e. in age and total length at release, as well as maturity stage at the time of recapture. Migratory fish tended to be older and longer than resident fish, but differences were not significant (independent samples 2-sided $t$-test, $\mathrm{p}=0.11$ and 0.31 , for age and length, respectively; Table 4). Visual inspection indicated that the incidence of mature or maturing gonads was higher in migratory fish $(64 \%)$ compared to resident fish $(28 \%)$; the difference, however, was not significant, probably due to 

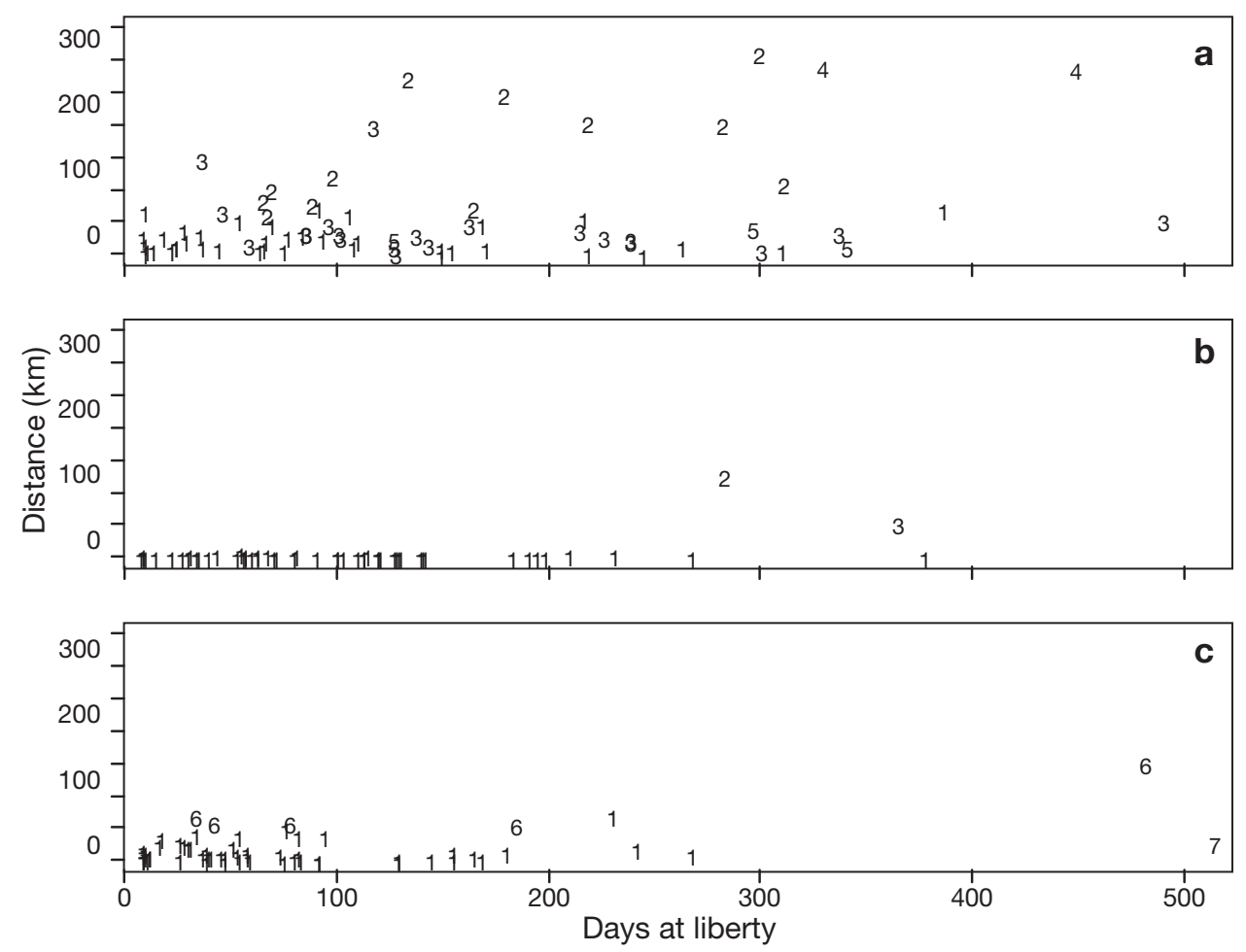

Fig. 6. Gadus morhua. Estimated shortest distance $(\mathrm{km})$ from the release point to the reported recapture position in relation to the number of days at liberty, for fish released in (a) the eastern Skagerrak, (b) Gullmar Fjord, (c) the Kattegat. Fish are labelled according to their designated migratory category (see 'Lightintensity based geolocation' for further description)

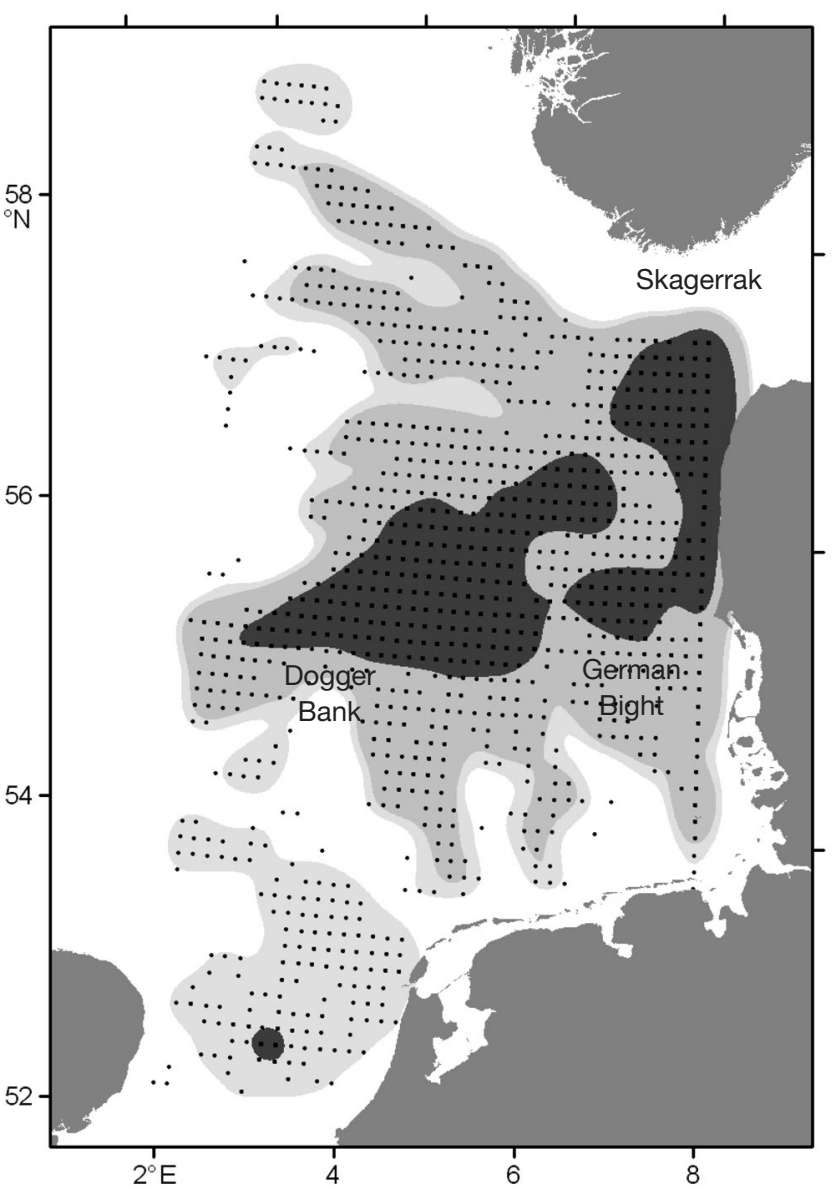

the low number of observations (Pearson chi-square; $\mathrm{p}=0.104, \mathrm{n}=29$ ).

\section{Seasonal variation in migratory activity}

The timing of migrations towards the North Sea/ western Skagerrak was analysed in fish categorised as 'migratory', and whose track records could be analysed for the whole period of time at liberty. Overall, the results indicated that migrations towards the North Sea (i.e. presence west of longitude $10^{\circ} \mathrm{E}$ ) occur predominantly during the spawning season between January and April (Brander 1994; our Fig. 9). Most recaptures from the North Sea or western Skagerrak were linked to the spawning season (9 out of 11 track records; Fig. 9a). For fish showing return migration back to the eastern Skagerrak, migration occurred during the spawning season in 17 out of 21 cases (Fig. 9b).

Fig. 7. Gadus morhua. Possible locations of cod that migrated into the North Sea (shaded areas). Dots show all temperaturevalidated geolocations derived from the tidal location method (TLM; see 'Materials and methods' for full explanation), of which many are superimposed. Shading shows kernel probability density function of the geolocations; dark, mid- and light shading: 50,75 and $95 \%$ probability contours, respectively 
Fig. 8. Gadus morhua. Mean monthly values of (a) daily maximal temperatures and $(b, c)$ maximum and minimum depths, respectively, between November 2003 and April 2006 for fish at liberty, originally tagged in the eastern Skagerrak. Grey: 'resident' phase at liberty, i.e. fish geolocated to be east of longitude $10^{\circ} \mathrm{E}$; black: 'migratory' phase at liberty, i.e. fish geolocated to be west of longitude $10^{\circ} \mathrm{E}$. Error bars: $95 \% \mathrm{CI}$; arrows: spawning periods between January and April

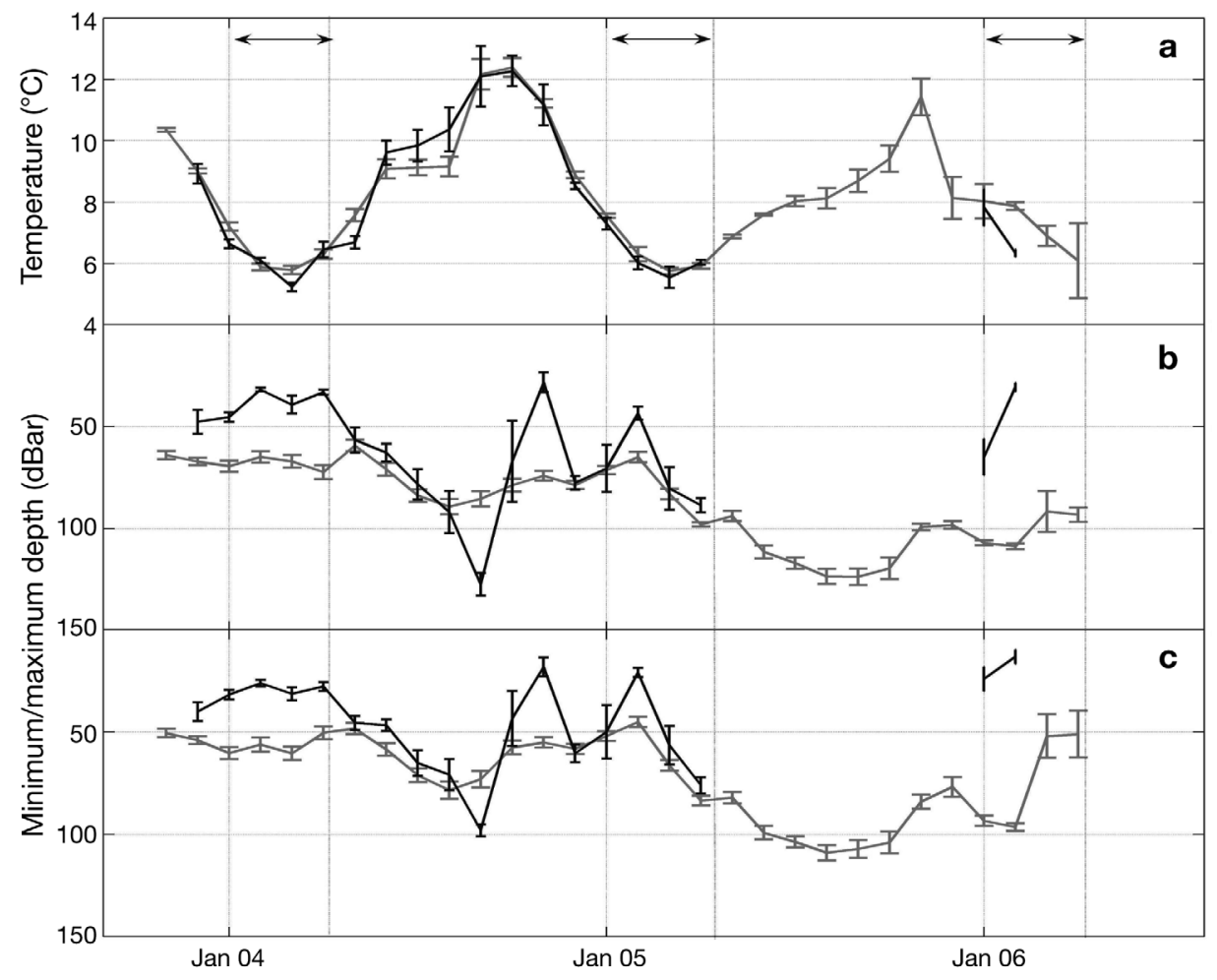

DISCUSSION

Table 3. Tidal geolocation modelling (mean latitude $(\mathrm{N})$ and longitude $(\mathrm{E})$ ), validated by comparing mean temperatures recorded by archival tags to averaged sea surface temperature for the whole period at liberty. Classification of migratory behaviour based on light geolocations are included for comparison (see 'Light-intensity based geolocation' for further explanations)

\begin{tabular}{|c|c|c|c|c|c|c|}
\hline $\begin{array}{l}\text { Light- } \\
\text { geolocation } \\
\text { classification }\end{array}$ & $\begin{array}{c}\text { Tidal- } \\
\text { geolocation } \\
\text { classification }\end{array}$ & Code & $\begin{array}{c}\text { Validated } \\
\text { tidal } \\
\text { locations }\end{array}$ & $\begin{array}{l}\text { Unique } \\
\text { locations }\end{array}$ & $\begin{array}{c}\text { Mean } \\
\text { latitude }\end{array}$ & $\begin{array}{c}\text { Mean } \\
\text { longitude }\end{array}$ \\
\hline 2 & 2 & 46 & 105 & 96 & 55.72 & 6.38 \\
\hline 1 & 3 & 53 & 89 & 87 & 56.46 & 4.39 \\
\hline 2 & 2 & 60 & 51 & 44 & 56.01 & 6.28 \\
\hline 3 & 3 & 74 & 29 & 29 & 55.60 & 5.00 \\
\hline 2 & 2 & 76 & 135 & 118 & 56.20 & 5.29 \\
\hline 3 & 3 & 79 & 88 & 78 & 56.16 & 6.52 \\
\hline 3 & 3 & 86 & 114 & 82 & 56.04 & 5.91 \\
\hline 6 & 6 & 163 & 480 & 302 & 54.98 & 5.02 \\
\hline 7 & - & 364 & 0 & & & \\
\hline 2 & 2 & 368 & 9 & 9 & 57.46 & 6.97 \\
\hline 3 & - & 380 & 0 & & & \\
\hline 2 & 2 & 383 & 17 & 17 & 57.64 & 7.20 \\
\hline 1 & 3 & 389 & 62 & 39 & 57.63 & 6.68 \\
\hline 2 & 2 & 403 & 82 & 67 & 58.06 & 4.78 \\
\hline 3 & 3 & 443 & 101 & 83 & 54.65 & 4.26 \\
\hline 2 & 2 & 449 & 0 & & & \\
\hline 3 & 3 & 516 & 145 & 124 & 55.80 & 5.77 \\
\hline 2 & 2 & 632 & 505 & 271 & 55.00 & 4.99 \\
\hline 2 & 2 & 699 & 287 & 121 & 53.81 & 3.72 \\
\hline 1 & 3 & 711 & 132 & 128 & 56.33 & 5.13 \\
\hline 3 & - & 713 & 0 & & & \\
\hline 3 & 3 & 719 & 184 & 44 & 55.86 & 6.12 \\
\hline 1 & - & 785 & 0 & & & \\
\hline
\end{tabular}

Taken together, these findings clearly suggest a strong behavioural component in the distribution pattern of cod in the eastern North Sea region, as cod tagged at different localities showed non-random, directional movements in agreement with the hypothesis that the cod population in this region comprises a mixture of resident and migratory stocks already discernible from other sources of information (e.g. Knutsen et al. 2003, 2004, Svedäng \& Svenson 2006). We think these directional movements represent migratory behaviour based on individual decision making of the fish, suggesting a philopatric tendency. The navigational clues for this natal homing behaviour are essentially unknown but merit further investigations.

The present study found pronounced differences in cod migratory behaviour between tagging locations in the Skagerrak-Kattegat area. A large and - over time-increasing proportion of the tagged cod off the Skagerrak coast moved in a westerly direction during 


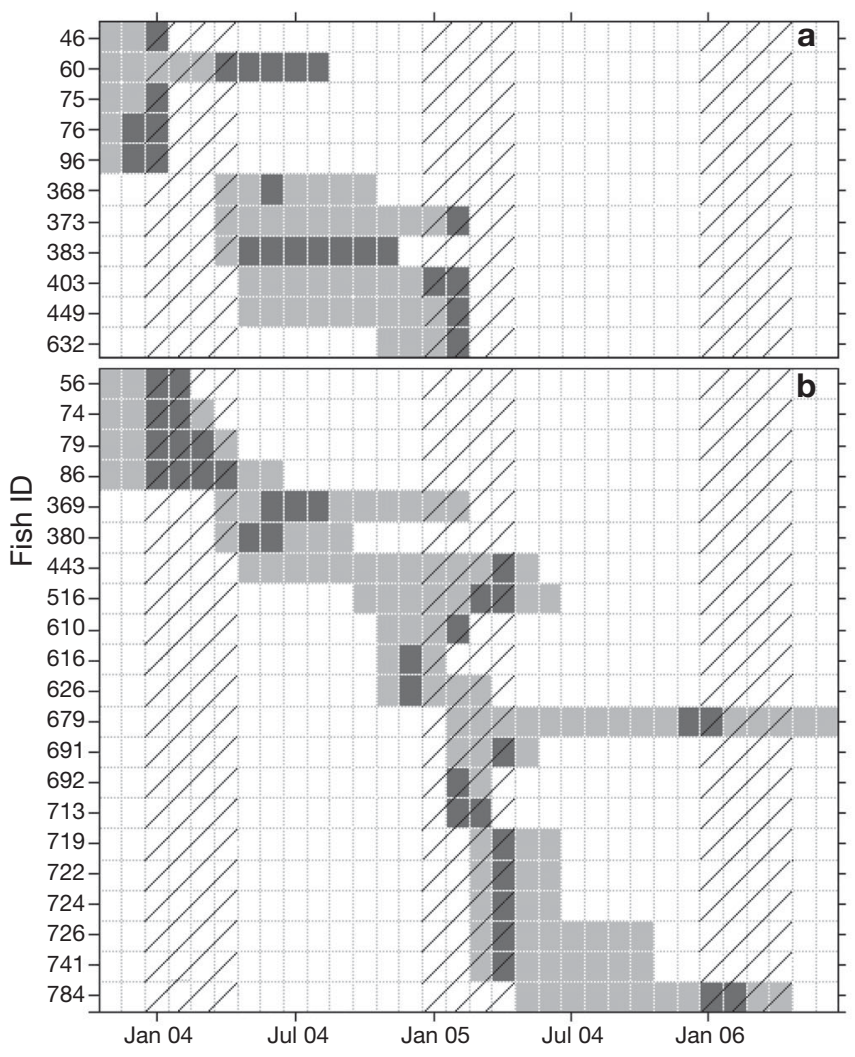

Fig. 9. Gadus morhua. Monthly geographical distribution between November 2003 and May 2006 for individual fish (a) recaptured in the western Skagerrak/North Sea, (b) recaptured in the eastern Skagerrak after visiting the western Skagerrak /North Sea. Grey, black bars: months in which fish were geolocated east or west, respectively, of longitude $10^{\circ} \mathrm{E}$. Hatched bars: spawning periods between January and April

their period at liberty. Some cod tagged in the Skagerrak also moved to the Kattegat, which could imply straying (cf. Windle \& Rose 2005), but might also have been due to homing of cod originating from the Kattegat. Cod tagged in the Gullmar Fjord showed a very resident behaviour (with the exception of 2 cod which showed North Sea bound migration). However, as most fish at this location were tagged just after the

Table 4. Gadus morhua. Age (yr) and length (mm) of retained fish originally tagged in the Skagerrak. The fish have been classified either as resident (Category 1 ) or migratory (Categories 2 to 4 ). Data are mean $\pm \mathrm{SD}$

\begin{tabular}{|lcccc|}
\hline Migratory classification & $\mathrm{N}$ & Mean & $\mathrm{SD}$ & $\mathrm{SE}$ \\
\hline Age & & & & \\
Resident & 22 & 2.27 & 0.88 & 0.188 \\
Migratory & 27 & 2.70 & 0.95 & 0.183 \\
Length & & & & \\
Resident & 27 & 504 & 94.1 & 18.1 \\
Migratory & 37 & 528 & 92.6 & 15.2 \\
\hline
\end{tabular}

spawning period, it is possible that a different tagging scheme would have revealed a higher proportion of North Sea bound migration. Most cod in the Kattegat indicated very limited movements, and the recapture positions were scattered around the release sites throughout the year. More extensive movements were only shown in fish tagged in the northern part of the Kattegat, notably in the vicinity of the offshoot from the Norwegian trench, The Deep Furrow.

The predominance of recapture positions along the northern coast of Jutland suggests that this might be the main migration route for cod from the eastern Skagerrak to the North Sea. One cod tagged in the south-eastern part of the Skagerrak swam across the Norwegian trench to a location close with the Norwegian coast. The depth profile connected with this movement has not been encountered in fish caught along the Danish coast, suggesting that migrations across the Norwegian trench might be of infrequent occurrence (cf. Danielssen 1969).

The geolocation results support the inferences we made based on mark-recapture data, but suggest that the migratory behaviour is more complex than we envisaged, showing less obvious dispersal patterns rather than simple unidirectional movements. Cod tagged off the eastern Skagerrak coast not only migrated towards the North Sea, they also showed return migrations back to the eastern Skagerrak after visiting the North Sea/western part of the Skagerrak. The presence of tagged cod west of longitude $10^{\circ} \mathrm{E}$ predominantly occurred during the spawning period. Tidal modelling - as well as variation in depth (habitat) selection between the resident and migratory phases for fish tagged in the Skagerrak-also supported this theory, as migrating fish showed a preference for shallower, and consequently slightly colder, waters during the spawning period. These behavioural differences might indicate that the fish had entered areas like the Greater and Lesser Fisher Banks in the eastern part of the North Sea, at least during the spawning season, which have been depicted as spawning areas from which cod eggs/larvae may drift into the Skagerrak (Munk et al. 1999). Regarding this migratory cod stock component, it may be hypothesised that spawning cod in the eastern North Sea constitute a subpopulation that utilises the strong counter-clockwise water circulation in the Skagerrak for dispersal of their propagules (Munk et al. 1999), and thereby enhance the opportunity for utilisation of large nursery areas. The return migrations to the eastern North Sea during the spawning period, as well as cod roaming around in the Skagerrak for feeding during other parts of the year, are consistent with the known life history patterns of cod in this region.

It was, however, also found that the migrations towards the North Sea during the spawning period 
were not only undertaken by sexually mature fish, since some fish were deemed to be 'non-maturing'. This observation might indicate that movements to spawning grounds also include non-reproductive individuals, although it cannot be judged whether this is indicative of prespawning spatial learning (cf. Windle \& Rose 2005) or simply indicates that the return migratory behaviour can be trigged before the onset of full maturation. It is also unlikely that the depicted migratory behaviour was related to feeding, since most migration runs were of short duration, and conditions are favourable for growth in the eastern Skagerrak, with abundant shrimp (Pandalus spp.; www.ices.dk) and herring (Clupea harengus L.) of various origins and size compositions (Ruzzante et al. 2006).

The results in the present study were also in accordance with the outcome from an earlier tagging study in the western part of the Skagerrak (Danielssen 1969). Cod off the northern Jutland coast between longitude 9 and $10^{\circ} \mathrm{E}$ were tagged between 1954 and 1965 . About $80 \%$ of the recaptures were made in the Skagerrak, but $14 \%$ of the tagged cod were also distributed over the entire eastern part of the North Sea. In addition, about $5 \%$ of the tagged cod were retained from the southeastern part of the Skagerrak/northern Kattegat. Most of the cod reported from the North Sea were caught during the most active part of the spawning period for cod in the North Sea, i.e. from February to April. Hence, these previous observations give strong support for conclusions made in this study of a migration route between the North Sea/western part of the Skagerrak and the eastern Skagerrak/northern Kattegat along the northern Jutland coast. In addition, a tagging study in the 1980s along the Swedish west coast observed that juvenile cod left the coastal habitats and migrated westwards (Pihl \& Ulmestrand 1993).

Nielsen et al. (2005) argued that the seemingly contradictory existence of reproductive isolation in fish populations which encounter few physical barriers with wide distributions and dispersal of pelagic eggs and larvae, was explained by retention of juveniles. For instance, genetic differentiation between cod in the western Baltic Sea and the Belt Sea in spite of larval drift was explained by selection in favour of hybrids, as homing was dismissed as unlikely. In contrast, genetic surveys along the Skagerrak coast have shown that the composition of young-of-the-year cod change from year to year consistently with year class strength variation in the entire Skagerrak (Knutsen et al. 2004). Thus, in years with a general low level of recruitment, juveniles were assigned to neighbouring coastal cod populations (i.e. reference material attained from adult, spawning fish), whereas in years with high levels of recruitment, the juveniles were, in contrast, assigned to reference populations sampled at spawning in the western part of the Skagerrak or in the eastern North Sea.

This study sheds light on the mechanism through which this separation between populations persists: juveniles dispersed at earlier life stages to the eastern Skagerrak and undertook return migrations in a westerly direction. It could also be argued that juveniles coming from the North Sea to the eastern Skagerrak or to the Kattegat do not have to make return migrations in order to find suitable spawning grounds; thus such energetically costly behaviour is not consistent with the view of juvenile retention as the prime structuring mechanism. Nor does the inflow of offshore recruits to the inshore seem to replenish resident, coastal populations to any greater extent (cf. Stenseth et al. 2006), judging by their relative genetic integrity (Knutsen et al. 2003).

Repeated homing of cod to spawning grounds has been observed in northwest Atlantic (Robichaud \& Rose 2004 and references therein). Robichaud \& Rose (2002) developed some hypotheses about short-range navigation mechanisms in cod: the grunting sounds that cod make while spawning and geo-magnetism could act as potential point sources. They also speculated that there was a social transfer of migratory behaviour, i.e. presence of maturing conspecifics, and memory of, for instance, bathymetric structures, especially during longer distance migrations. However, this study indicated that cod tagged at various localities show multidirectional movements, even in the presence of resident cod as in the Kattegat or in the Gullmar Fjord. It may therefore be hypothesised that impulses to return to natal spawning grounds are imprinted at earlier life stages, as they seem to be in herring in the North Sea region (Ruzzante et al. 2006).

Besides philopatric behaviour, the population structuring process is evidently also influenced by the degree of dispersal during early life stages and by straying, depending on the actual ecological and evolutionary settings (e.g. Robichaud \& Rose 2004). Nonetheless, if philopatric behaviour is recognised as the prime population structuring mechanism in marine fishes, it will have far-reaching consequences on the applicability of metapopulation theory to fishery science (McQuinn 1997, Smedbol et al. 2002) and on our perceptions in fisheries management (Smedbol \& Stephenson 2001). Importantly, if fish populations act as behavioural entities, degradation of population structures has to be considered as partly irreversible, at least on an ecological time perspective. Further integration of results from tagging studies with new molecular and chemical approaches will help to further clarify the role of behaviour in determining stock structure, especially concerning degree of reproductive isolation between spatially closely located spawning aggregations (cf. Wright et al. 2006). 
Acknowledgements. We are indebted to our colleagues AnneMarie Palmén-Bratt, Hans Hallbäck, Peter Jakobsson, Anders Svenson, the skipper and crew of R/V 'Ancylus' and the many fishermen who have cooperated with us by reporting recaptures and sending back tags and fish from all over the eastern North Sea region. We thank 3 anonymous referees for the constructive criticism of the study. All work was carried out under Swedish Central Laboratory Animals Board licence.

\section{LITERATURE CITED}

Brander KM (1994) The location and timing of cod spawning around the British Isles. ICES J Mar Res 51:71-89

Cardinale M, Svedäng H (2004) Recruitment and abundance of Atlantic cod, Gadus morhua, in the Kattegat-Eastern Skagerrak (North Sea): evidence of severe depletion due to a prolonged period of high fishing pressure. Fish Res 69:263-282

Danielssen DS (1969) On the migration of the cod in the Skagerrak shown by tagging experiments in the period 1954-1965. Fiskeridir Skr Ser Havunders 15:331-338

Hunter E, Aldridge JN, Metcalfe JD, Arnold GP (2003) Geolocation of free-ranging fish on the European continental shelf as determined from environmental variables. Mar Biol 142:601-609

Hunter E, Buckley AA, Stewart C, Metcalfe JD (2005) Migratory behaviour of the thornback ray, Raja clavata, in the southern North Sea. J Mar Biol Assoc UK 85: 1095-1105

Hutchinson WF, Carvalho GR, Rogers SI (2001) Marked genetic structuring in localised spawning populations of cod Gadus morhua in the North Sea and adjoining waters, as revealed by microsatellites. Mar Ecol Prog Ser 223: 251-260

Jonsdottir ODB, Danielsdottir AK, Naevdal G (2001) Genetic differentiation among Atlantic cod (Gadus morhua L.) in Icelandic waters: temporal stability. ICES J Mar Res 58: 114-122

Knutsen H, Jorde PE, André C, Stenseth Chr (2003) Finescaled geographical population structure in a highly mobile marine species: the Atlantic cod. Mol Biol 12: 385-394

Knutsen $\mathrm{H}$, André $\mathrm{C}$, Jorde PE, Skogen MD, Thuróczy E, Stenseth NC (2004) Transport of North Sea cod larvae into the Skagerrak coastal populations. Proc R Soc Lond B 271: $1337-1344$

McQuinn IH (1997) Metapopulations and Atlantic herring. Rev Fish Biol Fish. 7:297-329

Munk P, Larsson PO, Danielssen DS, Moksness E (1999) Variability in frontal zone formation and distribution of gadoid fish larvae at the shelf break in the northeastern North Sea. Mar Ecol Prog Ser 177:221-233

Musyl MK, Brill RW, Curran DS, Gunn JS and 6 others (2001) Ability of archival tags to provide estimates of geographical position based on light intensity. In: Sibert JR, Nielsen JL (eds) Electronic tagging and tracking in marine fisheries reviews: methods and technologies in fish biology and fisheries. Kluwer, Dordrecht, p 343-368

Nielsen EE, Grønkjær P, Meldrup D, Paulsen H (2005) Retention of juveniles within a hybrid zone between North Sea and Baltic Sea Atlantic cod (Gadus morhua). Can J Fish Aquat Sci 62:2219-2225

Editorial responsibility: Howard Browman (Associate Editorin-Chief), Storebø, Norway
Pawson MG, Jennings S (1996) A critique of methods for stock identification in marine capture fisheries. Fish Res 25: 203-217

Pihl L, Ulmestrand M (1993) Migration pattern of juvenile cod (Gadus morhua) on the Swedish west coast. ICES J Mar Res 50:63-70

Robichaud D, Rose GA (2002) The return of cod transplanted from a spawning ground in southern Newfoundland. ICES J Mar Res 59:1285-1293

Robichaud D, Rose GA (2004) Migratory behaviour and range in Atlantic cod: inference from a century of tagging. Fish Fish 5:185-214

Ruzzante DE, Taggart CT, Doyle RW, Cook D (2001) Stability in the historical pattern of genetic structure of Newfoundland cod (Gadus morhua) despite the catastrophic decline in population size from 1964 to 1994. Conserv Genet 2:257-269

Ruzzante DE, Mariani S, Bekkevold D, André C and 13 others (2006) Biocomplexity in a highly migratory pelagic marine fish, Atlantic herring. Proc R Soc B 273:1459-1464

Secor DH (2005) Fish migration and the unit stock: 3 formative debates: a review of ecological and historical issues related to stock connectivity and metapopulations. In: Cadrin SX, Friedland KD, Waldman JR (eds) Stock identification methods: applications in fishery science. Elsevier, Burlington, MA, p 17-44

Sibert J, Musyl MK, Brill RW (2003) Horizontal movements of bigeye tuna (Thunnus obesus) near Hawaii determined by Kalman filter analysis of archival tagging data. Fish Oceanogr 12:141-151

Smedbol RK, Stephenson R (2001) The importance of managing within-species diversity in cod and herring fisheries of the north-western Atlantic. J Fish Biol 59(Suppl A): $109-128$

Smedbol RK, McPherson A, Hansen MM, Kenchington E (2002) Myths and moderation in marine 'metapopulations'? Fish Fish 3:20-35

Svedäng H (2003) The inshore demersal fish community on the Swedish Skagerrak coast: regulation by recruitment from offshore sources. ICES J Mar Res 60:23-31

Svedäng H, Svenson A (2006) Cod (Gadus morhua L.) populations as behavioural units: inference from time series on juvenile cod abundance in the Skagerrak. J Fish Biol 69(Suppl C):1-14

Stenseth NC, Jorde PE, Chan KS, Hansen E, Knutsen $H_{\text {, }}$ André C, Skogen MD, Lekve K (2006) Ecological and genetic impact of Atlantic cod larval drift in the Skagerrak. Proc R Soc Lond B 273:1085-1092

Thorrold SR, Latkoczy C, Swart PK, Jones CM (2001) Natal homing in a marine fish metapopulation. Science 291: 297-299

Vitale F, Svedäng H, Cardinale,M (2006) Histological analysis invalidates macroscopically determined maturity ogives of the Kattegat cod (Gadus morhua) and suggests new proxies for estimating maturity status of individual fish. ICES J Mar Res 63:485-492

Windle MJS, Rose GA (2005) Migration route familiarity and homing of transplanted Atlantic cod (Gadus morhua). Fish Res 75:193-199

Wright PJ, Neat FC, Gibb FM, Gibb IM, Thordarson H (2006) Evidence for metapopulation structuring in cod from the west of Scotland and North Sea. J Fish Biol 69 (Suppl C): 181-199

Submitted: February 7, 2007; Accepted: June 30, 2007

Proofs received from author(s): August 17, 2007 